\title{
Food Service Providers' Attitudes Towards Nutrition and Food Handling Practices in Osogbo, Osun State, Nigeria
}

\author{
Awojobi A T \\ Department of Family, Nutrition and Consumer Sciences, Obafemi Awolowo University, Ile-Ife, Nigeria
}

Oladokun $0 \mathrm{~J}$

Department of Hospitality, National Institute for Hospitality and Tourism (NIHOTOUR) Osogbo Campus,

Osun State, Nigeria

Oladele 0 I

Department of Agricultural Economics and Extension North West University Mafikeng Campus, South Africa oladeleoladimeji@nwu.ac.za

\section{Doi:10.5901/mjss.2014.v5n27p1106}

\section{Abstract}

\begin{abstract}
The study assessed food service providers' attitudes towards nutrition and food handling practices in Osogbo, Osun State, Nigeria with foodservice providers randomly selected hotels and fast food restaurants in the town consisting of a total of 120 respondents. The study used of descriptive design and data was collected with the aid of structured questionnaire that sought information on the socio-economic characteristics of respondents, sources of nutritional knowledge, preparation and handling of food, nutrition attitude towards of food service providers. Frequencies and percentages were used to summarize the data collected and the hypotheses tested using chi-square. The result showed that there is a significant relationship between attitude of foodservice providers and food handling practices, age, sex and education while there is no significant relationship existed for income and marital status. The study concluded that majority of the hospitality outlets and food service providers in Osogbo have adequate favorable attitude towards nutrition and they use this during the process of food handling and preparation. Food handlers in hospitality outlets are to receive constant training and re-training on food and nutrition, food hygiene, food preparation and beverages and drinks.
\end{abstract}

\section{Introduction}

Food is a basic necessity for human living. It is the major source from which body nutrients are derived and when eaten can be absorbed into the body to be used as energy source, build body tissues, repair worn out tissue and nourish the body. The consumption of food is as good as food itself because the rate at which people eat would determine how vibrant they would be in their day to day activities in order to satisfy their social, economic, psychological needs and of course to satisfy hunger (Tenison,1980). Nigeria in her diversity has people of diverse culture with peculiar foods/cuisines that can be regarded to as regional favorites. In respect to food diversity in Nigeria, various foodservice or hospitality outlets such as hotel, restaurants, fastfood restaurants, bars and lots of others have been established to provide different foods in different places and at different times to satisfy people's hunger and meet with their gastronomic wants. As aforementioned, a lot of food are served in foodservice outlets, these include: intercontinental dishes such as pasta, egg meals, pottages, different types of soups, salads, fillets, pastry products etc, local foods such as iyan, amala, eba, lafun, fufu (peculiar to the Yorubas), akpu, ji-akpu, gari, osikapa, ede, (peculiar to the Ibos),ema, usi (peculiar to the Benins), suya, kilisi, tuwo (peculiar to the Hausas), these foods are ready to eat, exist in different amount of varieties, and served with varieties of soup peculiar to the people and their culture.

Advantages of patronizing and consuming foods offered by the foodservice outlets are not farfetched because they offer a wide range of food varieties, are easily and readily available, provide a dining experience away from home, have characteristic tastes and aroma and are served in clean and hygienic environments. In the same vein, disadvantages include the fact that food preparation and handling practices can expose foods to microbial contamination which can expose people to dietary diseases because of some additives/preservatives used, It can also lead to malnutrition in the sense that food nutrients might be altered. This necessitates the present study. 
Food service systems are the businesses, institutions and companies that are responsible for any meal prepared outside the home. The industry include restaurant, school and hospital cafeteria, catering operation and many other formats. Food service systems have developed over recent years and are aimed to overcome the shortage of skilled labor and reducing operational costs. Consumer demand for convenience has led to these prepared meals being adapted for the rapidly growing 'home meal replacement sector'. The continual growth and development of food provision services are dynamic because a food service unit is scientifically planned and operated to provide a successful and effective food provision service.

Fast food also known as Quick Service restaurant is the term given to foods that can be prepared and served very quickly while any meal with low preparation time can be considered to be fast food, typically the term refers to food sold in restaurants or stores with preheated or cooked ingredients (CDC, 2009). The concept of ready cooked food for sale is closely connected with urban development. In ancient Rome, cities had street stands that sold bread and wine. In the French-speaking nations of west Africa, roadside stands in and around the larger cities continue to sell as they have done for generations, a range of ready to eat, char-grilled meat sticks known locally as brochettes. A British form of fast food is the sandwich, popularized by John Montagu in 1962 when he wrapped dried meat in bread so as not to interrupt his work.

In 2006, the global fast food market grew by $4.8 \%$ and reached a value of 102.4 billion and a volume of 80.3 billion transactions 2008 study was conducted worldwide counting the number of fast foods restaurants per person. Thus, United Kingdom has claimed this title with Australia second and the United states third. England alone accounted for 25\% of all fast foods. However, fast food chains have come under criticism over concerns such as claimed negative effects and claims of cultural degradation via shifts in people's pattern away from traditional foods. While it is clear that fast food is generally unhealthy, it is not obvious a priority that changes in the availability of fast food should be expected to have an impact on health. Fast food are sold in various foodservice outlets such as restaurants, bistros, convenience stores of filling stations with the commonest being fast food restaurant. Nearly from its inception, fast food has been designed to be eaten 'on the go'. Today, many people eat fast food instead of home-made-foods; the reason is that fast food is fast, cheap and convenient. Some fast food restaurants are located and operate worldwide. Below is a list of some fast food restaurants: McDonald's- located in 126 countries and on 6 continents and operates over 31,000 restaurants in the world; Burger King- has more than 11,100 restaurants in more than 65 countries, located in 25 countries; Subway- with approximately 39,129 restaurants in 90 countries; Pizza hut- located in 97 countries with 100 locations in China, Taco Bell has 278 restaurants located in 14 countries aside the United States, Mr. Biggs- located across Nigeria, Captain cook, Tantalizers and Chicken republic

As more consumers have gradually moved toward healthy living, fast-food restaurants (the providers and handlers) want to be able to accommodate them. Fast-food restaurants' addition of healthy menu items has helped the industry get back on its feet post-recession and Regardless of how it's branded, healthy alternatives will increase due to consumer demand (Anderson, Bell, Adamson and Moynihan, 2001). Awareness may also shift in relationship to new information and/or new educational messages, as indicated by the decrease in mentions of fibre as a dietary factor associated with cancer and the increase in mentions of fruits and vegetable (Guthrie, et al. 2009). In addition, the gender construct created by society has led to the division of roles played by men and women within a family where women are given the responsibility of food provision which entails planning, purchasing, storing, preparation and disposal. Overall, there is strong empirical evidence that women possess more cooking competence required for several stages of the home food production chain. At younger ages, the acquisition of cooking knowledge and skills is mainly through mothers, other family members and cooking classes; but as people get older, their learning source shifts to cooking books. Furthermore, as one gets older, his or her techniques and confidence of cooking competence increases and improves (Sabrina Ternier, 2010).

To emphasize how cooking experiences assist nutrition knowledge in achieving healthy diets, it can be useful to view nutrition knowledge as the 'what to eat' and the cooking knowledge as the 'how to make it'. This clearly shows the relationship between the two factors towards dietary behavior. In a study of young adults, $23 \%$ of males and $18 \%$ of females reported that lack of cooking competence created a barrier to food preparation. If one knows what foods are healthy to eat, or what preparation techniques are healthier (fried egg versus poached egg) but is unable to make that healthy meal, his or her knowledge cannot be fully realized. Because nutrition is a relationship between food preparation and health, there is the need for foodservice providers to have adequate nutritional knowledge so as to prepare food in a way that the nutritional content would not be lost. However, not many foodservice providers are trusted to have adequate nutrition knowledge and food handling practices and this has led to the conclusion that fast foods or foods eaten in hotels are not nutritious or healthy. In the same vein, researches have been carried out and revealed that consumers are now aware of the nutritional implication of food that are not prepared properly, hence the need for foodservice providers to put the knowledge of nutrition into practice if they want to remain in the business. FAO (2008) pointed out that the chemical 
reactions that occur during cooking vary as the item(s) being cooked and the conditions under which the cooking takes place are put into consideration. The things we cook (the animals and/or plants or their products) and the additives that are included in the production of the food we get (if any) are in most cases, complex organic compounds; and there can be a lot of different compounds in just one type of food. Much of the chemistry of cooking relates to the application of heat to these compounds, and heat generally has a tendency to affect nutritional contents of foods. It is against this backdrop, that the present study is designed to investigate nutrition knowledge among foodservice providers in Osogbo capital city, Osun state of Nigeria.

The objective of this study is to assess the foodservice providers' attitudes towards nutrition in Osogbo, Osun State, Nigeria. Specific objectives the study assessed the nutritional and hygiene knowledge of food service providers, investigated the sources of nutrition knowledge of foodservice providers, ascertained the awareness of foodservice providers on the health implication of food additives used and determined food preparation and handling practices among foodservice providers. Significant relationships between socio-economic characteristics, attitude towards nutrition and food handling practices of foodservice providers were explored.

\section{Methodology}

The research was carried out in Osogbo Township, Osun state. Osogbo is the capital of Osun state which has 30 local government an d one area office. Osun state is an inland state in south-western Nigeria. Its capital is Osogbo which is bounded in the north by Kwara State, in the east partly by Ekiti State and partly by Ondo State, in the south by Ogun State and in the west by Oyo State. It lies on the railway from Lagos to Kano. The Local Government Area has an area of $47 \mathrm{~km}^{2}$ and a population of 156,694 (NPC 2006). Most of the population is members of the Yoruba ethnic group. Being the administrative seat of the state, the town harbors civil servants, businessmen and women, students, artisans, and so on who on so many occasions eat outside their homes due to the nature of their jobs or lifestyles. World cultural heritage site, Osun Osogbo Grove, is a tourism destination which attracts thousands of tourists to the capital city. In order to meet peoples need and satisfaction in this regards, many hotel restaurants and fast food restaurants have been established, some of which include: Royal spring hotel, Living spring hotel, Delightsome hotel, Sazo hotel, Capital hotel, Ostrich restaurant, Spices, Mr. Biggs, Tantalizers, Captain cook, Finger licking and a host of others who offer foodservices like fried rice, jollof rice, salads, fried chicken, fried turkey, fried fish, fried beef, pastries and confectionaries (meat pie, fish pie, burgers, buns, doughnuts, pan cake, gala), ice cream, yoghurt, puddings, etc. some provide indigenous foods such as iyan, fufu, semovita, amala, eba, served with various soups such as okro soup, vegetables, ewedu, gbegiri, egusi.

This study adopted survey research design and the population of this research comprised all staff of fast food outlets, foodservice providers and hotels in Osogbo, Osun State.From the list of fast food outlets and hotels in Osogbo were provided by hospitality department of Ministry of Home Affairs, Tourism and Culture, Osun State, 6 hotel restaurants and 6 fast food restaurants were randomly through ballot. From the selected hotel and fast food outlets restaurants and 60 respondents were selected each from food handlers and service providers to give a sample size of 120 . A structured which comprised of personal/demographic, socio-economic characteristics, sources of nutrition knowledge, preparation, handling and nutrition knowledge of foodservice providers was used for data collection. The data from the study were analyzed using both descriptive and inferential statistics for hypotheses testing (Chi-square).

\section{Results and Discussion}

Table 1 shows the respondents' ages between 18 and 60 years. It shows that majority (55.8\%) of the respondents fell between the age bracket of 26 and 40years, 38.3\% fell between the ages of 18 and $25 y$ years, while only $5.8 \%$ fell between the age bracket of 41 and 60years. This implies that majority of the foodservice providers fall between the ages of 26 and 40years, this is because they are in their productive or economic age. This is in agreement with the findings of Sabrina Ternier (2010) that people of this age bracket have more cooking skills. The findings showed that majority (51.7\%) of the respondents were females while the rest (48.3\%) males. This implies that individuals involved in foodservice production are mostly females. This also supports the findings of Sabiena Ternier (2010) that females are more involved in cooking and food handling.

The findings also revealed that majority (41.7\%) of the respondents earned an average income within $(10,000$ $25,000), 25.0 \%$ of the respondents' income level was less than $10,000,23.3 \%$ earned an average income within $(26,000-$ 40,000 ), $4.2 \%$ of the respondents' income level was more than $70,000,3.3 \%$ of the respondents earned an average income within 56,000 and 70.000 while only $2.5 \%$ of the earned an average income between 41,000 and 55,000 . This implies that majority (41.7\%) of the foodservice providers earn between 10,000 and 25,000 . The table revealed that 
majority (67.5\%) of the respondents were single, $29.2 \%$ of the respondents were married, $1.7 \%$ of the respondents were separated, while only $1.7 \%$ of the respondents were widows. This implies that majority of the respondents are still single with the highest percentage distribution of $81(67.5 \%)$. The study revealed that majority $(71.7 \%)$ went to tertiary institutions, $28.3 \%$ of respondents stopped at secondary school secondary, while none $(0.00)$ of the respondents stopped at primary school. This implies that majority $(71.7 \%)$ of the foodservice providers in the study area were well educated.

Table 1: Percentage distribution of respondents based on personal and Socio-economic characteristics of respondents

\begin{tabular}{|c|c|c|}
\hline Personal Characteristics & Frequency & Percentages \\
\hline \multicolumn{3}{|l|}{ Age } \\
\hline $18-25$ & 46 & 38.3 \\
\hline $26-40$ & 67 & 55.8 \\
\hline $41-60$ & 7 & 5.8 \\
\hline \multicolumn{3}{|l|}{ Gender } \\
\hline Female & 62 & 51.7 \\
\hline Male & 58 & 48.3 \\
\hline \multicolumn{3}{|l|}{ Income (Naira) } \\
\hline$<10000$ & 30 & 25.0 \\
\hline $10000-25000$ & 50 & 41.7 \\
\hline $26000-40000$ & 28 & 23.3 \\
\hline $41000-55000$ & 3 & 2.5 \\
\hline $56000-70000$ & 4 & 3.3 \\
\hline$>70000$ & 5 & 4.2 \\
\hline \multicolumn{3}{|l|}{ Marital Status } \\
\hline Single & 81 & 67.5 \\
\hline Married & 35 & 29.2 \\
\hline Separated & 2 & 1.7 \\
\hline Widowed & 2 & 1.7 \\
\hline \multicolumn{3}{|l|}{ Education } \\
\hline Secondary & 34 & 28.3 \\
\hline Tertiary & 86 & 71.7 \\
\hline
\end{tabular}

Table 2 shows that majority (67.5\%) of the respondents worked in hotel restaurants while the rest $(32.5 \%)$ worked in fastfood restaurants. This implies that majority (67.5\%) of the foodservice providers in the study area worked in the hotel restaurants; this is because there are more hotels than fastfood restaurants in the study area. Table 2 shows that high percentage (54.8\%) of nutrition knowledge was acquired from school, $17.1 \%$ of nutrition knowledge was acquired from family and friends, $14.4 \%$ of nutrition knowledge was acquired from the media while only $13.1 \%$ was from the internet. From table 2, a high percentage (34.0\%) of food additives used during food preparation was preservatives, $27.7 \%$ were sweetners, $17.0 \%$ were colourings, $11.7 \%$ of food additives used were icing while only $9.6 \%$ of food additives used were others such as honey and locust beans.

Table 2: Service outlets, information sources and use of food additives among respondents

\begin{tabular}{|c|c|c|}
\hline & Frequency & Percentages \\
\hline Service Outlet & & 67.5 \\
\hline Hotel & 81 & 32.5 \\
\hline Fastfood & 39 & 14.4 \\
\hline Information sources & & 54.8 \\
\hline Media & 21 & 17.1 \\
\hline School & 80 & 13.1 \\
\hline Family and friends & 25 & \\
\hline Internet & 20 & 17.0 \\
\hline Food Additives & & 27.7 \\
\hline Colouring & 32 & 11.7 \\
\hline Sweetners & 52 & 34.0 \\
\hline Icing & 22 & 9.6 \\
\hline Preservatives & 64 & 18 \\
\hline Others & 18 & \\
\hline
\end{tabular}


From table 3 , the findings revealed that majority (85.0\%) of the respondents agreed that overcooking of food can cause nutrient loss while only $15.0 \%$ disagreed to this. Also, majority of the respondents (81.7\%) agreed that food additives can have negative implication on nutrition of consumers while only 18.3\% disagreed. In addition, majority (90.0\%) of the respondents agreed that Hazard Analysis Critical Control Points are important guidelines in food preparation and handling while $10.0 \%$ disagreed.

From table 3, majority (93.3\%) of the respondents agreed that vegetable are more nutritious than snacks, while $6.6 \%$ disagreed. The findings further revealed that majority (71.7\%) of the respondents agreed that unsaturated oils are more nutritious than saturated oils while $28.4 \%$ disagreed. Also, majority $(75.0 \%)$ of the respondents agreed that grilling of meat retains more nutrients than frying while only $25 \%$ disagreed. In addition, majority (92.5\%) of the respondents agreed that selling a more nutritious food would make a more nourished consumers while only $7.5 \%$ disagreed.

Table 3: Percentage distribution of respondents' attitudes towards nutrition and food preparation and handling practices

\begin{tabular}{|l|c|c|c|c|}
\hline Attitudinal statement & SA & A & D & SD \\
\hline Cooking food is better than frying & $65(54.2)$ & $48(40.0)$ & $3(2.5)$ & $4(3.3)$ \\
\hline Frying of food can cause nutrient loss & $45(37.5)$ & $54(45.0)$ & $17(14.2)$ & $4(3.3)$ \\
\hline Overcooking of food can cause nutrient loss & $62(51.7)$ & $40(33.3)$ & $12(10.0)$ & $6(5.0)$ \\
\hline $\begin{array}{l}\text { Sweetners, Flavouring, Icing, colouring, thickners, preservatives, are examples } \\
\text { of food additives }\end{array}$ & $58(48.3)$ & $56(46.7)$ & $5(4.2)$ & $1(0.8)$ \\
\hline Food additives can have negative implication on nutrition of consumers & $39(32.5)$ & $59(49.2)$ & $19(15.8)$ & $3(2.5)$ \\
\hline $\begin{array}{l}\text { Hazard Analysis Critical Control Points are important guidelines in food } \\
\text { preparation and handling }\end{array}$ & $49(40.8)$ & $59(49.2)$ & $12(10.0)$ & $0(0.0)$ \\
\hline Overconsumption of sugary food can cause malnutrition & $55(45.8)$ & $57(47.5)$ & $8(6.7)$ & $0(0.0)$ \\
\hline Eating too much of snacks can implicate nutrition status of consumers & $39(32.5)$ & $71(59.2)$ & $8(6.7)$ & $2(1.7)$ \\
\hline Eating fruits after a meal makes it more nutritious & $58(40.3)$ & $59(49.2)$ & $2(1.7)$ & $1(0.8)$ \\
\hline Fast foods are nutritious for consumption & $28(23.3)$ & $58(48.3)$ & $25(20.8)$ & $9(7.5)$ \\
\hline Fast food can be more nutritious & $26(21.7)$ & $60(50.0)$ & $29(24.2)$ & $5(4.2)$ \\
\hline Vegetables are more nutritious than snacks & $72(60.0)$ & $40(33.3)$ & $7(5.8)$ & $1(0.8)$ \\
\hline Majority of fast food contain high calorie & $38(37.7)$ & $59(49.2)$ & $22(18.3)$ & $1(0.8)$ \\
\hline Using too much calories can cause obesity & $51(42.5)$ & $56(46.7)$ & $12(10.0)$ & $1(0.8)$ \\
\hline Unsaturated oils are more nutritious than saturated oils & $30(25.0)$ & $56(46.7)$ & $26(21.7)$ & $8(6.7)$ \\
\hline Butter, coconut oil and palm oil are examples of saturated oils & $34(28.3)$ & $69(57.5)$ & $13(10.8)$ & $4(3.3)$ \\
\hline Castor oil, groundnut oil and margarine are examples of unsaturated oil & $37(30.8)$ & $59(49.2)$ & $20(16.7)$ & $4(3.3)$ \\
\hline Grilling of food retains more nutrients than frying & $54(45.0)$ & $53(44.2)$ & $10(8.3)$ & $3(2.5)$ \\
\hline Lean or white meats are better than red meat & $42(35)$ & $48(40.0)$ & $25(20.8)$ & $5(4.2)$ \\
\hline Selling more nutritious food would make a nourished customer & $49(40.8)$ & $62(51.7)$ & $9(7.5)$ & $0(0.0)$ \\
\hline $\begin{array}{l}\text { Curry is an anti-oxidant and therefore important in the nutrition of food } \\
\text { consumers }\end{array}$ & $28(23.3)$ & $63(52.5)$ & $23(19.2)$ & $6(5.0)$ \\
\hline
\end{tabular}

From table 4, it shows that there is significant relationship between age, sex and level of education, while there is no significant relationship between income and marital status and food handling practices. This implies that respondents' age, sex, and level of education affect the food handling practices of foodservice providers. On the other hand, income and marital status do not affect the food handling practices of foodservice. Hence, the null hypothesis is rejected.

Table 4: Relationship socio-economic characteristics of respondents and attitude towards food handling practices

\begin{tabular}{lllclr}
\hline Variable & Chi square & Critical region & $\begin{array}{c}\text { Degree of } \\
\text { freedom }\end{array}$ & $\begin{array}{c}\text { Level of } \\
\text { significance }\end{array}$ & Remark \\
Age & 8.597 & 3.283 & 5 & & S \\
Income & 0.245 & 6.308 & 5 & & NS \\
Sex & 11.036 & 2.154 & 5 & 0.05 & S \\
Marital status & 0.983 & 6.720 & 5 & & NS
\end{tabular}

\section{Conclusion}

It was discovered that more females are involved in foodservice systems, the reason may be attributed to the fact that 
women are more involved in food preparation and service, also to the increasing industrialisation which enables more women to be employed. The findings also revealed that majority of the foodservice providers have good knowledge of nutrition and of food preparation and handling. This can be attributed to the fact that majority of the respondents are educated and know the proper food preparation and handling practices as well as the importance of Hazard Analysis Critical Control Points. Finally, since the foodservice providers have good nutrition knowledge, it can be concluded that fast foods outlets and hotels in the study area prepare nutritious and safe for consumption foods contrary to the general opinion of people that fast foods are bad and unsafe for consumption.

\section{References}

Anderson, A.S. Bell, A. Adamson, A. and Moynihan, P. (2001). A questionnaire assessment: validity and reliability issues. Public Health 5(3): 497-503p.

Centre for Disease control (2009) Ensuring Food Safety, Writing Your Own Food Safety Plan The HACCP Way. A Guide Food Service Operators. http://www.bccdc.ca/NR/rdonlyres/1A068D5D-3350-4D1C-A356-D8C6D62B7DB9/0/EnsuringFoodSafetyHACCPWay .pdf Accessed September 2014

FAO. (2008) Climate Change and Food Security: A Framework document. Food and Agricultural Organisation of the United Nations, Rome. 1-93p

Guthrie J F., Brenda M. Derby and Alan S. Levy (2009) What people know and they do not know about nutrition, 243-280p

Larson, N.I., Perry, C.L., Story, M. and Neumark-Sztainer, Dyson. (2006). Young adults are associated with better diet quality. J Am Diet Assoc.106p.

Sabrina Ternier (2010) Understanding and measuring cooking skills and knowledge as factors influencing convenience food purchases and consumption. Studies by Undergraduate Researchers at Guelph, Vol 3, No 2.

Tenison, M.H. (1980) The Cook's Handbook: David McKay \& Co. Inc. New York. USA. 